\title{
Humanização e loucura, em busca do humano que dialoga saúde
}

\section{| 1 Jonathan Filippon, ${ }^{2}$ Luciane Prado Kantorski |}

Resumo: Investindo na necessária relação teórica entre as Políticas de Humanização e de Saúde Mental do sistema de saúde brasileiro, o presente artigo defende, através do diálogo teórico entre ambas, a ideia de que as propostas expressas em tais políticas são respostas coerentes às principais contradições do intrincado sistema público de saúde nacional. Neste intento são apresentadas: as bases teóricas das citadas políticas ministeriais; suas relações com a sociedade que as demandou enquanto políticas públicas; e, finalmente, a maneira como a conjunção de ambas fornece contribuições essenciais à continuidade do Sistema Único de Saúde (SUS). A metodologia ensaística foi utilizada, de acordo com bibliografia metodológica atualizada, relacionando autores e suas contribuiçôes com o objetivo de defender o ponto de vista dos autores do artigo. Conclui-se que o incentivo público à protagonização da sociedade contraria a lógica biologicista dos cursos de formação de profissionais de saúde e horizontaliza as relações humanas do SUS, fortificando-o e dando-lhe razão essencial de existência à sociedade brasileira.

> Palavras-chave: saúde mental; humanização; controle social.

\footnotetext{
${ }^{1}$ Mestre em Enfermagem Psiquiátrica e Ciências pela Escola de Enfermagem de Ribeirão Preto, Universidade de São Paulo. Endereço eletrônico: jonathanfilippon@gmail.com

2 Doutora em Enfermagem Psiquiátrica pela Escola de Enfermagem de Ribeirão Preto, Universidade de São Paulo. Endereço eletrônico: kantorski@uol.com.br
}

Recebido em: 12/07/2011. Aprovado em: 21/12/2011. 
Os debates teóricos recentes sobre a humanização do cuidado em saúde têm se acercado de propostas centradas na capacidade dialógica das relaçôes entre gestores, profissionais e usuários, ressalvando sua função necessariamente (AYRES, 2007; DESLANDES, 2006). A relação entre diálogo humano e produção política é redundante, não só na produção de políticas públicas de saúde, como também na própria constituição da existência humana, que se afirma como tal a partir da troca de informações entre os homens, significando a noção do ente social em relação à percepção de si. Pensando assim, que sem comunicação não há relação humana, objetivamos afirmar neste ensaio teórico a obrigatória relação entre o diálogo e a produção de políticas públicas, visando ao reforço teórico do sistema de saúde público brasileiro. $\mathrm{O}$ ensaio teórico consiste em uma exposição lógica e reflexiva, caracterizada pela rigorosidade de argumentação e pelo alto nível de interpretação e opiniōes pessoais dos autores (MARCONI; LACATOS, 2010). Acreditamos, portanto, ser esta a metodologia mais adequada às características do assunto proposto no presente artigo.

A dicotomia entre as políticas de saúde ministeriais e as práticas em saúde nos municípios brasileiros é a revelação empírica da incapacidade dialógica entre esses dois extremos do sistema de saúde nacional. Aparentemente, há uma fenda na comunicação entre os dois limites do mesmo todo que denominamos Sistema Único de Saúde (SUS).

O momento histórico é propício a tal discussão. $\mathrm{O}$ ainda recente marco de 20 anos da legislação que regulamenta o SUS (BRASIL, 1990) permite-nos avaliar as conquistas alcançadas e as falhas cometidas, revelando novas necessidades para a continuidade da Reforma Sanitária iniciada na década de 70. Mas há um detalhe - na verdade, um imenso detalhe: decorridos pouco mais de 30 anos dos principais processos nacionais de conquista democrática e sanitária da história recente brasileira, seus protagonistas, pessoas que partilharam existências em uma luta comum, da qual faziam parte através de valores e necessidades pessoais, precisam de apoio para a continuidade do processo. As novas gerações de trabalhadores em saúde e usuários do sistema adentram-no como um constructo dado, pronto, com falhas e vícios institucionais que, ao serem desligados do processo histórico no qual estão inseridos, podem inadvertidamente ser encarados como parte integrante do sistema público de saúde. Incorremos no imenso risco de perpetuar as atuais falhas pertinentes ao controle social caso não sejam retomados valores 
e significados muito presentes para a geração que vivenciou em seu cotidiano a rigidez do regime autoritário da ditadura militar e buscou em específicas doutrinas teóricas as bases do constructo que se apresenta hoje como o sistema de saúde nacional (PAIM, 2007). É necessário significar para a atual geração de trabalhadores em saúde a importância da produção política individual, protagonista e atuante em seu lócus de ação; criar um senso de pertença ao coletivo, ao sistema público de saúde em si. É nesse terreno que pretendemos contribuir com algumas fundamentaçôes teóricas, essenciais à continuidade do sistema público de saúde brasileiro.

Acreditamos que as respostas para os desafios que ora se impõe em múltiplas alternativas e caminhos como todo processo social (complexo e multifacetado) possam ser indicadas nas políticas públicas de saúde vigentes no país, principalmente no tocante às suas doutrinas teóricas. Buscar no cerne do problema respostas às suas contradições é salutar ao processo histórico da construção de uma política de saúde equânime, universal e integral, pois se remonta assim ao princípio básico da filosofia (MARTÍN, 2004; BARBOSA, 2008). Cremos que em nossas contradições estão as melhores respostas. Os objetivos específicos deste ensaio são: alargar as possibilidades de relações dialógicas no SUS em suas bases teóricodoutrinárias e significar existencialmente o sistema público de saúde para as novas gerações de trabalhadores da área. Para tanto, propomos neste ensaio a reflexão teórica entre dois dos campos da política nacional em saúde que, pensamos, buscam responder a grandes contradições do sistema público brasileiro: a política de humanização da saúde e a política de saúde mental. Estas, apesar da diferença de foco, compartilham, não de forma gratuita, de semelhante base teórico-filosófica/ doutrinária, justificando o estabelecimento do possível diálogo entre ambas.

É essencial ao estabelecimento da discussão a clareza de nossos posicionamentos teóricos acerca do entendimento da loucura e da humanização (ou humanismo). Loucura, como fenômeno social, é uma produção necessária à sociedade que a gera, bem como seus mecanismos biopolíticos de cuidado e controle (FOUCAULT, 2008); humanizar é basicamente investir na radicalidade do homem enquanto tal, élocalizar sua existência na coletividade e, portanto, ressalvar sua responsabilidade junto às existências que o cercam (ALEKSANDROWICZ; MINAYO, 2005).

Através do estabelecimento de territórios comuns entre as políticas públicas de saúde mental e a política nacional de humanização, estabeleceremos nossa 
discussão. Defendemos neste ensaio que a busca pela voz do socialmente construído não cidadão, calado pelo diagnóstico da loucura, associada à horizontalidade das relações de gestão e de cuidado humanizadoras, formam um constructo essencialmente democrático - base do processo civilizatório de efetivação do direito constitucional à saúde.

É essencial a ressalva de que as políticas públicas são resultado de uma demanda social prévia e são entendidas aqui como açôes de governo. Tais ações são resultantes da democracia ora vigente, sendo frutos da politica competitiva (pleito eleitoral) somada à política constitucional (COUTO, 2005). As políticas aqui citadas não diferem desse quadro de gênese, cada qual com sua história e importância social, inseridas no campo maior que as abarca, o Sistema Único de Saúde brasileiro.

\section{Discussão}

As políticas de saúde mental e o processo de construção da humanização da saúde podem ser observados e analisados por meio de variadas facetas: seus processos históricos de construção; seus papéis enquanto fenômenos sociais brasileiros (principalmente o movimento de reforma psiquiátrica); sua função de proporcionar a vivência cidadã e constitucional às pessoas em sofrimento psíquico e à população em geral (BACKES et al., 2007; ALVERGA et al., 2005). Entendemos que tais facetas de análise, mesmo que não esgotadas, vêm sendo objeto de estudo de inúmeros pesquisadores brasileiros (DESLANDES, 2006; PAIM, 2007; BACKES et al., 2007; ALVERGA et al., 2005; PINHEIRO; LUZ, 2007). Portanto, balizamos este ensaio nos seguintes prismas de análise, que entendemos como ainda pouco discutidos.

No primeiro, as políticas de saúde mental, assumindo a posição filosófica e essencialmente teórica da representação do louco na sociedade, aquele que personifica o excessivo exercício de diagnose contemporâneo resultante das influências positivistas dos métodos científicos (PIRELLA et al., 2008). Para tudo, há uma explicação biologicista; para todo comportamento errante há medicamento a ser ingerido na busca da cura e da normatização da existência. Seu caráter necessário é o de pensar o homem, estabelecendo locais para a absorção e cuidados de pessoas em sofrimento psíquico a partir do prévio fracasso dos grandes manicômios. 
No segundo, a base teórica da política de humanização da saúde representa a produção filosófica mais próxima das práticas democráticas, por seu caráter de pensar a relação entre os homens. Ao propor uma série de dispositivos humanizadores (Clínica Ampliada, Gestão Participativa e Cogestão, Defesa dos Direitos dos Usuários, Valorização do Trabalho e do Trabalhador, Acolhimento, Fomento das grupalidades e projeto "Memória do SUS que dá certo"), tal política reforça a necessidade dialógica entre os vários atores do sistema de saúde. Propõem-se, através de seus dispositivos de ação, espaços que possibilitem o encontro entre os vários representantes do coletivo social da saúde: cuidadores, população e gestores; demonstram-se a estes a sobreposição, superposição e relação entre seus papéis. A vivência prática e cotidiana da política de humanização reforça o necessário encontro com o outro, real e despojado dos papéis interpretados. Reforça o encontro da pessoa do outro, e não seu papel institucional, o objeto que aqui definimos como interpretação social (LAHIRE, 2008) e sobre o qual discutiremos a seguir.

Apesar da afirmação representativa dos prismas, é necessário esclarecer que a metáfora é um apoio teórico para a análise e a discussão do assunto proposto, já que tais extremos constituem um todo, um constructo social total. A visível menor complexidade de concretizar tais políticas sobre determinados prismas de análise aqui nos serve apenas metodologicamente, a fim de organizar a retórica do texto.

\section{As políticas nacionais de Humanização e de Saúde Mental}

Reconhecemos nas políticas de humanização e de saúde mental processos de construção da própria sociedade, ora demonstrados através de normatizações ministeriais, ora apresentados por manifestações de agrado ou desagrado da população. Não as dividimos aqui em programas de governo ou movimentos sociais. Elevamo-nas a um todo -- pertencente à sociedade -- somando-as: governo $e$ sociedade. A característica de suas propostas, criadas a partir de uma demanda social específica, justifica sua escolha para este ensaio. A necessária humanização do sistema público de saúde e a capacidade de lidar com seus loucos apontam caminhos de desconstrução de processos cristalizados de gestão, financiamento, trabalho e vivência da coisa pública - aqui representada pelos serviços de saúde. Nos impasses nos quais tais políticas se debruçam, estão demonstradas contradições cruciais das Reformas Sanitária e Psiquiátrica brasileiras que, em 
seus erros extremados (desumanização e exclusão dos loucos) podem apontar caminhos para importantes rupturas com recorrentes problemas que o sistema público de saúde brasileiro apresenta.

As propostas da política de humanização da saúde brasileira buscam a aproximação do sistema com as práticas em saúde propriamente ditas, entendidas não apenas em ações curativas, como também nas vivências individuais propiciadas pelo sistema de saúde a todos seus entes constituintes: conselheiros de saúde, gestores do sistema, profissionais em saúde e população em geral. O foco de suas propostas encontra-se no processo de produção humana, individualmente protagonista, porém necessariamente inserida em um contexto de coletivo de pessoas, valorizando as ações que propiciam o diálogo entre os constituintes do sistema de saúde.

Seguir os preceitos do SUS (integralidade, universalidade e equidade) constituiu-se em um imenso desafio prático e político a partir de sua concretização no final da década de 1980 (PAIM, 2007). Como uma das respostas mais recentes a tal desafio, a partir de razoável produção teórica, o Ministério da Saúde brasileiro propôs a chamada Política Nacional de Humanização. Ao definir o foco de ação de tal política, ela dimensiona a amplitude do significado de produção de saúde de forma humanizada:

Por humanização entendemos a valorização dos diferentes sujeitos implicados no processo de produção de saúde: usuários, trabalhadores e gestores. Os valores que norteiam essa política são a autonomia e o protagonismo dos sujeitos, a responsabilidade entre eles, o estabelecimento de vínculos solidários, a construção de redes de cooperação e a participação coletiva no processo de gestão. (BRASIL, 2010a, p.8)

A Política Nacional de Humanização (PNH) é colocada em seu documento base (BRASIL, 2010a) como uma política pública transversal às instâncias de gestão e ação do sistema público de saúde, implicada em traduzir os princípios básicos do SUS em práticas de saúde dos sujeitos, dos equipamentos e da rede de saúde em si. Para tanto, propõe-se a orientar as práticas de gestão e ação em saúde a partir das experiências práticas de seus trabalhadores e usuários, humanizando os sujeitos e suas ações cotidianas através de trocas solidárias de experiências; em outras palavras, busca trazer a subjetividade do homem para dirimir a mecanização ora vivida nas diversas esferas sociais de gestão e práticas de saúde do SUS. Necessariamente, o entendimento de tal humanização, passa pela "mudança nos modelos de gestão em sua indissociabilidade" (p.19), a tal 
dicotomia entre práticas e planejamento à qual nos referimos na abertura deste

ensaio. O combate a essas brechas do sistema dá-se ao catalisar a resolutividade e agilidade do mesmo, tornando-o mais acolhedor na ambiência para trabalhadores e usuários e politizando-o (no sentido de trocas políticas entre iguais) através da articulação entre formação e práticas em saúde.

Através de ações práticas a serem implantadas nos municípios, a PNH propõe o fortalecimento do sistema investindo em seu principal constituinte: as pessoas que o utilizam, que trabalham nele ou que o gerem. Os limites entre usuário, gestor e trabalhador em saúde são salutarmente desfocados, pois tais papéis se sobrepõem, trocando de lugar conforme a biografia individual de cada cidadão vai sendo escrita ao longo de sua vida.

As diretrizes, linhas-guia da PNH, são as seguintes:

- Clínica Ampliada: propõe a clínica que considere o subjetivo do sujeito, dando foco à saúde individual e não priorizando a doença. Apesar da necessária universalidade do diagnóstico clínico, é necessário ultrapassá-lo para atingir as peculiaridades de cada indivíduo em suas características únicas (BRASIL, 2009a);

- Gestão Participativa e Cogestão: trata-se da horizontalização das decisões nas gestôes municipais de saúde por meio de colegiados formados por trabalhadores, gestores e usuários catalisando democraticamente o sistema. A cogestão é "um modo de administrar que inclui o pensar e o fazer coletivos, sendo, portanto, uma diretriz ético-política que visa democratizar as relações no campo da saúde" (BRASIL, 2009b, p.10);

- Defesa dos Direitos dos Usuários: propõe divulgar e auxiliar na conscientização dos usuários do sistema de saúde em relação aos seus direitos constitucionais;

- Valorização do Trabalho e do Trabalhador: nesta diretriz, é reconhecido o desgaste emocional e físico dos trabalhadores (SOARES; CUNHA, 2007); por meio de ações de cuidado à sua saúde física e mental, este é um eficaz meio de humanização e reprodução de saúde, a partir justamente da atenção aos profissionais do sistema. A PNH aposta na criação de espaços mais prazerosos e saudáveis de trabalho para catalisar o protagonismo dos indivíduos em seu encontro cotidiano de experiências (BRASIL, 2011);

- Acolhimento: a implantação do acolhimento como postura profissional e sistemática de todos os serviços de saúde municipais aproxima a população dos 
dispositivos de cuidado em saúde. Através do acolhimento e da democratização do acesso, o sistema é horizontalizado em suas relações (BRASIL, 2010b);

- Fomento das grupalidades, coletivos e redes: a partir da constituição da saúde como um direito do cidadão, a organização de redes regionais e descentralizadas, coletivos sociais e grupos de interesse comum passaram a ser estratégias fundamentais para a manutenção e enriquecimento do SUS (BRASIL, 2009c);

- Construção da Memória do "SUS que dá certo": por intermédio de diversas mídias, eventos e encontros, a PNH se compromete com a construção, divulgação e manutenção do arquivo de memórias do "SUS que dá certo", com a intenção de valorizar o sistema de saúde junto à sociedade (BRASIL, 2010a).

A PNH é, portanto, um conjunto de ações baseadas em propostas de aposta radical na subjetividade dos sujeitos constituintes do SUS - trabalhadores, usuários e gestores. Com essa base, a política de humanização espera atingir resultados como a redução na espera de atendimento, maior integração entre os participantes do sistema, criação de espaços de garantia de direitos através das unidades de saúde e, finalmente, formação de gestores/trabalhadores/usuários dentro da própria política de humanização em "uma perspectiva formativa, participativa e emancipatória, de aprender-fazendo e fazer-aprendendo" (BRASIL, 2010a, p.32).

A outra política nacional à qual nos referimos, a de saúde mental, possui em sua constituição a marca dos valores apregoados a partir do movimento de reforma psiquiátrica proposto pela psiquiatria democrática italiana (AMARANTE, 2007). Os serviços possuem base comunitária e orientação descentralizada de atendimento, de modo a possibilitar o trânsito do usuário por seus diversos dispositivos - diferenciando-se do modelo anterior, que se centrava na figura do médico psiquiatra, no diagnóstico patológico e no remédio psicotrópico. Por meio de equipes multidisciplinares e do conhecimento de outras ciências (psicologia, ciências sociais, enfermagem, educação física, antropologia, artes visuais, entre outros), a política de saúde mental possui como filosofia a atenção ao outro enquanto ser único em sua condição.

Não é a intenção deste ensaio a total retomada dos valores da reforma psiquiátrica, já amplamente divulgados e discutidos nos meios acadêmicos e nos novos dispositivos de saúde mental: Centros de Atenção Psicossocial (CAPS), Núcleos de Atenção Psicossocial (NAPS), Moradas Terapêuticas e outros dispositivos antimanicomiais. Tampouco pretendemos discutir os determinantes 
históricos e sociais que nortearam a implantação de tais serviços. O que a nós interessa é a peculiar capacidade dialógica e política do movimento de reforma psiquiátrica brasileiro, que, mesmo submetido ao entendimento social acerca da loucura que destitui o indivíduo de sua condição de cidadão, possibilitou-lhe voz de reivindicação, essencial à garantia de direitos. $\mathrm{O}$ movimento da defesa de não cidadãos, destituídos de tal condição pelo atual entendimento social acerca da loucura, é (ou foi) radicalmente político e democrático em suas posições teóricas. Ações práticas como o Programa "De Volta Para Casa", que prevê incentivo financeiro a ex-moradores de instituições psiquiátricas e apoio da rede de saúde mental ao retorno à sociedade, são exemplos claros de uma política que aposta na biografia individual do cidadão. Anteriormente a aposta psiquiátrica era no diagnóstico e na interminável cura do louco (FILIPPON, 2009).

Estendendo tais argumentos à discussão proposta, afirmamos que podemos, utilizando-nos de estratégias semelhantes às da reforma psiquiátrica brasileira, incentivar o uso da voz política e cidadã junto aos que não foram destituídos dela pelo diagnóstico de loucura: os cidadãos brasileiros, constitucionalmente possuidores do direito à saúde. Acreditamos nessa possibilidade. Para tanto, é necessário resgatar o entendimento do termo política, essencial à reforma da saúde mental brasileira, que possui em seu cerne de açôes o ideal democrático, devolvendo (ou fornecendo pela primeira vez) a voz cidadã aos loucos, oferecendolhes oportunidade de apropriar-se dos assuntos concernentes a sua saúde e, por que não, de sua doença - questionando-a inclusive. Possuímos a clareza de que as experiências democraticamente exitosas (como a formação de assembleias de usuários que buscam o diálogo entre familiares, trabalhadores e indivíduos em sofrimento psíquico) ainda são raras no vasto plano da realidade dos municípios brasileiros. Ações políticas como a criação de associações de usuários, familiares e trabalhadores foram essenciais para o processo de conquista da legislação nacional promulgada em 2002, que propõe dispositivos não manicomiais de cuidado. Os últimos dez anos, a partir da promulgação da lei nacional de reforma psiquiátrica em 2002 (BRASIL, 2001), foram decisivos para a implantação de novos dispositivos substitutivos ao manicômio, dada a implantação de 1620 CAPS no Brasil (BRASIL, 2010c). Eles não se bastam a si, contudo, para serem reais substitutos aos variados manicômios: os concretos (hospícios), os mentais (preconceitos) ou ainda os sociais (discriminação). A apropriação da 
porção política por parte dos entes do processo social -- os militantes da saúde mental -- foi o poder disparador de novos modos de cuidar/olhar a loucura. A matriz da política de saúde mental comunga com o entendimento de política do humanismo: um envolvimento de homens, com valores próprios e histórias individuais, responsáveis por sua existência na coletividade.

Recorremos às considerações filosóficas para estabelecer um diálogo entre a Política Nacional de Humanização e a Política Nacional de Saúde Mental. Para tanto, buscamos produções que enfatizam o protagonismo humano, principalmente no tocante ao homem político. Utilizamos as reflexôes filosóficas como uma ponte de ligação - de forma literal. Tal analogia neste ensaio ilustra a relação de idas e vindas, de trocas em constante trânsito de um extremo ao outro, de interdependência comunicativa que o campo filosófico proporciona com o objetivo de reforço teórico do SUS. Dois continentes geograficamente separados (as políticas de saúde mental e de humanização) comunicando-se por uma ponte (a filosofia).

As políticas de saúde mental e humanização oscilam entre as práticas em saúde (ações) e seus balizadores teóricos (discussões científicas). A dicotomia entre teoria e prática é presente em inúmeros trabalhos recentes acerca de ambos os temas (ALEKSANDROWICZ; MINAYO, 2005; PAIM; NAOMAR, 1998; SANTOS-FILHO; BARROS, 2007; FILHO, 2008) e aproxima-se da relação aparentemente díspar entre disciplinas ditas "humanas" ou "científicas". A oposição entre ciência e humanismo é um antigo problema, que remete às questôes filosóficas sobre a autonomia do homem ou o determinismo prévio de suas ações. Simplificando a questão: o homem é autônomo e decide suas açôes como ser livre baseado no uso de sua racionalidade, ou a realidade humana (assim como suas açôes) é de alguma maneira predeterminada por leis naturais que regem o mundo (e os homens) independentemente da capacidade humana racional de compreendê-lo, com suas leis?

Ultimamente, tais questôes foram agudamente problematizadas a partir das propostas filosóficas neodarwinistas da biologia evolutiva: se o mundo é determinado por leis naturais (que regem a ciência), o homem não é um ser autônomo e, portanto, é despido de livre-arbítrio, contrariando o pensamento racional e o próprio entendimento do homem como sendo protagonista de sua existência. Sendo assim, a base da compreensão científica positivista desde 
Descartes contraria-se filosoficamente. Esse é um dos principais temas para o

humanismo contemporâneo, pois, segundo Aleksandrowicz e Minayo (2005),

qualquer investigação sobre a possibilidade humana de direcionar livremente os atos do indivíduo em prol de uma ética de respeito e solidariedade para consigo mesmo e seu semelhante, conduzindo ao bem-estar e à felicidade [como as políticas de humanização e saúde mental $]^{1}$, repousa sobre a questão fundamental da autonomia e do determinismo.(ALEKSANDROWICZ; MINAYO, 2005, p.514)

Dada a problematização acerca do livre-arbítrio a despeito do estabelecimento de leis naturais que negam a possibilidade de protagonização ao homem, passemos ao próximo tópico, no qual o aproximaremos à sociedade que o rotula.

\section{O Humanismo, o Louco e a Sociedade}

O humanismo, como corrente filosófica, centra o foco de suas reflexôes na existência do homem e em seu protagonismo político na relação com os outros através do diálogo (MARTÍN, 2004). Essencial ao movimento de rompimento filosófico do pensamento humano com as amarras da religiosidade e do misticismo, o humanismo é a base da negação que o racionalismo científico viria a exercer a partir dos séculos XVIII e XIX em relação à religião católica no pensamento filosófico ocidental, marcando de maneira indelével o pensamento científico moderno e contemporâneo. Nasce a expressão "comprovação científica" para designar a verdade irrefutável proposta pelos meios lógicos do pensamento e do estabelecimento/busca de leis que rejam o mundo. A questão que emerge na filosofia contemporânea é: o estabelecimento de leis naturais aplica-se ao homem e sua existência?

Não é de forma gratuita que o século XX traz, filosoficamente, a retomada das questōes metafísicas (outrora questionamentos religiosos ligados à cristandade), agora em relação ao homem consigo mesmo - a subjetividade humana. Alguns autores chegam a considerar como uma negação à metafísica a busca da subjetividade humana do século XX (BORNHEIM, 2007), caracterizada por procurar a resposta às questôes filosóficas na própria existência do homem, opondo-se aos pensadores dos séculos XV, XVI e XVII, que buscavam explicações para a existência humana sempre na relação com Deus. Nietzsche chega a afirmar, ao final do século XIX, que Deus morreu, e que foi preciso ao homem matar a Deus para encontrar-se a si mesmo (NIETZSCHE, 2002), referindo-se à subjetivação individual do pensamento. Obras como Ser e Tempo 
de Heidegger e O Ser e o Nada de Jean-Paul Sartre são expoentes do pensamento filosófico do século XX e exemplos claros da inquietação humana em relação ao estabelecimento de verdades constantes e indiscutíveis. Ambos os escritos pensam a existência humana em meio aos maiores conflitos bélicos e genocidas da história da humanidade, por pessoas que vivenciaram em seu cotidiano as influências das duas Grandes Guerras Mundiais e seus extermínios em massa (de ambos os lados das trincheiras).

Contrariamente, os humanistas dos séculos XV, XVI e XVII foram considerados em suas épocas, pelo poder vigente, ora religioso, como os incautos, os subversivos, os não adaptados - os loucos. Pois as obras dos loucos de outrora são constantemente retomadas na contemporaneidade, na busca de possibilitar a transformação social ético-política por meio da radicalidade de suas ideias, dada a base filosófica de inúmeros trabalhos científicos a respeito da produção política no SUS (PINHEIRO et al, 2007; SANTOS-FILHO; BARROS, 2007).

Ao retomar o sentido da Política de Humanização do SUS em suas diretrizes (protagonismo e autonomia dos sujeitos; estabelecimento de redes solidárias e de responsabilidade mútua; participação em processos decisórios de maneira coletiva), observamos que sua base científica remete ao humanismo em sua essência, à radicalidade do entendimento do homem como responsável por sua existência e de outros e no investimento na autonomia do indivíduo em benefício da sociedade solidária (no sentido literal da palavra, relacionada à virtude social - virtu - descolada da imagem social de caridade relacionada ao solidarismo). O humanismo (ou humanização em uma linguagem contemporânea) se aproxima da loucura enquanto rompimento, no entendimento da renovação da estética social, na valorização do homem em sua autonomia, no agir criativo. A junção da criatividade de ambas - políticas de cuidado à loucura fora das instituiçôes manicomiais e políticas de humanização - proporciona o rompimento de barreiras e, contraditoriamente aos olhos sociais mais grosseiros, civilizam a própria civilização auxiliando na acentuação da virtu social.

Intentamos utilizar de forma recorrente neste ensaio a palavra louco, propositalmente. Dispensamos seu uso como adjetivo. Aqui, para nós, louco é substantivo - concreto, obviamente. O louco substantivo, este que existe e é a representação da própria sociedade e suas dificuldades em lidar com a porção que não se adapta, que incautamente insiste em resistir aos processos de diagnose 
e tratamento de suas loucuras nega a existência do louco adjetivo. O adjetivo é

o estigma, é a jocosidade da sociedade consigo mesma - "com o fulano não é possível conversar, ele é louco"; utilizar a loucura como adjetivo é assumir uma postura contraditória. A loucura adjetivada traz o peso do julgamento moral, e este a aproxima da periculosidade, da violência, da dependência, da incapacidade - todas elas produçóes da própria sociedade que as julga e classifica em tom pejorativo. A contradição que denominamos jocosidade contra si mesmo por parte da sociedade é exatamente esta: produzir a loucura, julgá-la, desqualificála e amnesicamente não encará-la como produção própria. Portanto, para este ensaio, o louco passa ao largo de uma palavra pejorativa; é a designação da sociedade a si mesma, às suas contradições. Não ignoramos aqui o processo de adoecimento, de patologização do indivíduo através da loucura; aquilo a que nos contrapomos, aqui, é a construção social de cunho moral acerca dos ditos loucos, das concepções pré-postas em relação à loucura e ao pensamento delirante e, por que não, radicalmente criativo, como a produção política que propomos na junção filosófica humanização/loucura.

\section{O encontro com o outro}

O pressuposto básico das relações dialógicas presume uma troca de informações entre indivíduos iguais, independente da forma de comunicação. $\mathrm{O}$ diálogo, nesse caso, independe da voz, podendo dar-se através de comunicações formais (documentos, cartilhas, leis), manifestações físicas ou quaisquer outras formas comunicativas. Não nos deteremos nas formas comunicativas em si, objeto de trabalho de estudiosos da área da comunicação social; nosso interesse centra-se no encontro que a comunicação exige, na essência do significado da produção política proporcionada por esse encontro. Retomando a filosofia e seu início, na vivência romana da polis, o logos era a capacidade de comunicação do indivíduo durante a assembleia. Nesta, a discussão (o diálogo), a votação entre iguais possibilitava um resultado decisório, deliberativo, admitido como lei, de maneira política, no sentido etimológico da palavra - para todos.

Acreditamos que as relações previamente instituídas nos papéis de gestor, de trabalhador e de usuário predeterminam as informações a serem trocadas nos encontros institucionais entre esses papéis sociais, bloqueando sua capacidade de diálogo. Como um trabalhador que se relaciona com seu objeto de trabalho, seja 
ele qual for, os atores institucionais assim relacionam-se uns com os outros. Ao lidarmos com objetos e não com pessoas, não há encontro humano e, menos ainda, produção política através do diálogo. Assim, dispomos o melhor do Sistema de Saúde (o encontro humano) em uma esteira perversamente taylorista (CAMPOS, 1998), que infinitamente reproduz o instituído, o já dado, o entendido como parte do sistema. O encontro humano pressupõe criação, unicidade, ineditismo, humanidade. A relação com o objeto pressupõe técnica, serialidade, reprodução de algo já existente, repetitividade. Desde as relações individuais entre cuidadores, gestores e frequentadores dos serviços de saúde até as relações intra e interinstitucionais de suas esferas legais constituintes (secretarias, departamentos, ministérios, conselhos), há uma predeterminação social dos indivíduos que as protagonizam, um encontro de papéis sociais previamente instituídos, distante das subjetividades individuais, negando toda a produção filosófica que embasa o Sistema Único de Saúde.

Coloquemos em exemplo o que afirmamos até agora, lembrando que, para tanto, baseamo-nos na experiência dos autores enquanto trabalhadores/gestores atuantes do SUS - o exemplo é hipotético e não baseado em estudo sistematizado metodologicamente; porém, justificamos seu uso pela sua essencialidade ao aproximar o discurso filosófico e a práxis (objetivo prático deste ensaio).

A conclusão a que chegamos é essencial para a contextualização prática da consequência de falta de humanização no sistema de saúde: um usuário busca acessar um serviço qualquer de saúde acreditando que receberá antibióticos para o tratamento de um resfriado e tem sua demanda recusada. Mesmo que tal desejo contrarie cientificamente o próprio cuidado em saúde (um resfriado viral, como o deste exemplo, entre 3 a 5 dias naturalmente é curado em indivíduos hígidos sem o uso de medicamentos), confirma-se na perspectiva do usuário o que está popularmente definido: o sistema não funciona. Provavelmente o usuário pré-conceberá negativamente seus futuros acessos ao sistema de saúde. $\mathrm{O}$ funcionário que o atenderá, e que possui os mesmos valores sociais do usuário a respeito do sistema, igualmente pré-conceberá o próximo atendimento conforme suas experiências prévias, mesmo possuindo o conhecimento científico para o cuidado em saúde. Seres racionais que são, funcionário e usuário pré-conceberão seu encontro, seu diálogo. Será encarado como "mais uma tentativa frustrada de acesso" por um, e "mais um a que terei de dizer não" pelo outro. Pagamos 
um alto preço por tais pré-concebimentos, ceifando na origem as possibilidades de cuidado, de produção de saúde, de estabelecimento de redes solidárias, de protagonismo dos sujeitos. Nós mesmos, enquanto usuários, trabalhadores e gestores, contraditoriamente desumanizamos o sistema.

Ressaltamos aqui que a relação dialógica exemplificada é uma dentre as infinitas possíveis entre seus seres constituintes. Abrangem as relações dialógicas predeterminadas desde reuniōes de trabalho entre profissionais do sistema, conselhos de saúde de todos os níveis, assembleias, e tantos outros espaços de encontro humano que aqui não citamos. Ao preestabelecermos tais encontros, findamos seu significado antes mesmo que ocorram.

Ayres (2007), a partir de Gadamer, Habermas e Heidegger, propõe relevantes reflexões filosóficas que se impõem a partir da dicotomia das modernas práticas técnicas em saúde e seu distanciamento da ação humana necessariamente envolvida no cuidado em saúde. Convida-nos a pensar no resultado do devir individual do profissional e da pessoa a ser cuidada, somado às ações técnicas em saúde e experiências práticas do não profissional. Adaptando a proposta filosófica de Heidegger de fusão de horizontes no encontro com o outro, Ayres aproxima a discussão da prática clínica, encarando a relação entre cuidador e ser cuidado como produtora de projetos de felicidade - quando realmente humana e originalmente pessoal. $\mathrm{O}$ autor brasileiro ressalta, ainda, o caráter político de tal resultado.

Somos resultado do encontro com o outro, com os outros em sociedade, e tais encontros fornecem a devida identificação de nossas atribuições sociais: de sermos pais, trabalhadores, brasileiros ou qualquer outra identificação que o valha. Somente assumimos esses papéis sociais por sermos considerados pelos outros como pais, trabalhadores ou brasileiros. Tal constatação aparentemente simples do ponto de vista do entendimento concreto esconde questões filosóficas mais profundas. Vejamos: vivemos coletivamente na polis, e a ela pertencemos. Mesmo que alguns sejam avessos a seus conceitos e determinações, nascemos nela e adequamos nossas vivências e devires à porção social em que nos encontramos. As ideias, os pensamentos que pré-concebemos individualmente, nossos óculos de entendimento do mundo, são como um monóculo. Pensamos individualmente e, caso não nos dispamos de pré-concebimentos, predeterminamos o que irá ocorrer em qualquer fato social: desde a vida em família até a participação entendida como política - em um conselho de saúde por exemplo. É preciso 
vivenciar o conceito de coletivo para a superação da dicotomia persistente entre indivíduo e sociedade (ESCOSSIA; KASTRUP, 2005).

A reflexão que se busca aqui é a de que, de acordo com a hipótese que propomos, o mesmo mecanismo que determina que um indivíduo com diagnóstico de hipertensão arterial vá, recorrentemente, aos serviços de saúde sem conseguir controlar sua doença ou sua condiçãa de doente, ocorre com os planejamentos em saúde coletivamente construídos. Eis uma dificuldade comum à política de humanização e às políticas de saúde mental, e que percorre todo o sistema público de saúde brasileiro. Predeterminamos a condição de doente do indivíduo e sua dificuldade em controlar sua doença antes mesmo que o atendimento de saúde ocorra. Vemos como profissionais a Hipertensão Arterial Crônica, o objeto diagnóstico, e não o indivíduo, único em sua existência. Semelhante mecanismo ocorre de maneira coletiva com as políticas de saúde, fadadas ao fracasso quando institucionalizadas, serializadas e distanciadas das relaçōes humanas em portarias e mecanismos regulatórios. Porém, em ambos os casos, tanto o indivíduo doente quanto as políticas de saúde necessitam do atendimento clínico e dos mecanismos regulatórios que os massificam e distanciam do cuidado aos homens, fim para o qual foram criados. A resposta à contrariedade dessa relação está no encontro humano que existe quando ambos estão acontecendo: atendimento à saúde $\mathrm{e}$ execução coletiva de suas políticas. Tal momento é a vivência prática do conflito filosófico entre a existência humana e o estabelecimento de leis que a rejam: queremos que o hipertenso siga uma rotina de tratamento, igual a todos - apesar de todos serem distintos em sua existência única enquanto homens.

A recorrente vivência da desestrutura aparente do sistema de saúde e de seus mecanismos legais de controle social, somada ao clima que vivemos de desconfiança nas instituições democráticas (MOISÉS, 2005), gera sentimentos desesperançosos nas pessoas que os executam. É comum que os usuários há muitos anos inseridos nos fóruns de participação popular das ações em saúde, quando questionados sobre a ineficiência do SUS, respondam utilizando expressões como: "é assim mesmo", "neste país é isso aî" ou ainda "é sempre a mesma coisa mesmo, fazer o quê?". ${ }^{2}$ Ao transformarmos os encontros humanos em simples relaçôes de objetos sociais, condenamos o sistema de saúde ao predeterminismo pasmaceiro e reacionário, estagnando a relação do pensar e do fazer saúde. A relação sempre extremada entre uma ponta que atende e outra ponta que planeja é 
preciso ser repensada. Recorramos a Deleuze e Guattari, que, ao comentarem as extremidades do pensamento científico e das relações humanas, propõem: "não é fácil perceber as coisas pelo meio, e não de cima para baixo, da esquerda para a direita ou inversamente: tentem e verão que tudo muda." (MOISÉS, 2005, p.35) É claro que não é simples. Os autores sabem disso e ressalvam afirmando que não é fácil. Mas é possível. Para vencer a relação dicotômica entre indivíduo e sociedade, de serialização da vida, propomos uma tentativa de novidade constante. Consideramos que

os objetos [políticas de saúde] não causam nem determinam nada, ao contrário, eles são determinados, produzidos pela relação. [...] os conceitos de prática e de relação remetem a um plano produtor de mundo e de sentido [...] (ESCOCIA; KASTRUP, 2005, p.298)

A estagnação dialógica predetermina ações de planejamento e construção histórico-social das políticas de saúde brasileiras, mesmo as que sequer foram planejadas até o presente momento. Não se trata de fatalismo, ou mesmo de predeterminismo que condene as presentes ou futuras políticas de saúde nacionais. Trata-se de uma sugestão reflexiva que ultrapasse o pensar da humanização em saúde a partir apenas das práticas técnicas de seus profissionais. Diante do quadro truncado com que nos deparamos é necessário extrapolar a reflexão humanista para os atos políticos envolvidos no fazer saúde em todos os seus níveis. Para isso, precisamos de diálogo, o mesmo proposto claramente pela política brasileira de saúde mental. Almejamos aqui abarcar os espaços em que dividimos a polis, entendidos como todos os espaços sociais onde podemos demonstrar ideias, concepções e, quiçá, fusões de horizontes pessoais em direção a um sistema de saúde ainda mais democrático que o que possuímos.

Grosso modo, a expressão cunhada por Heidegger (fusão de horizontes) e adaptada por Ayres (2007) para a clínica em saúde, condiz com o momento em que indivíduos culturalmente diferentes, a partir de seu encontro de existências, passam a dividir valores, crenças ou percepções. A partir de tal adaptação, Ayres propõe os projetos de felicidade, produtores de mundo e de sentido para os atores sociais envolvidos na produção de saúde - trabalhador e usuário. É esse o real encontro com o outro, a negação à relação objetal que o cotidiano e a desconfiança democrática insistem em forçar-nos a vivenciar. Mesmo que sejamos indivíduos imersos em uma mesma cultura ocidental, possuímos individualmente valores, crenças e experiências diversas. Os padrōes de consumo, esvaziados de sentido 
real, são impostos à sociedade pelo capitalismo. A mídia publicitária impõe modos de existir padronizados, com fórmulas autômatas de felicidade, em projetos de vida insossos e irreais. Há um achatamento da riqueza da diversidade existencial humana, que não sobrevive aos achaques insistentes da padronização social e das maneiras de ser feliz, ditadas sempre a partir do acúmulo financeiro. O outro, porém, sempre está ali, à espera da construção de projetos de felicidade comuns nas fusões de horizontes possíveis pelos encontros de existências que o sistema de saúde oferece - em todos seus níveis. É preciso ver o humano que há por detrás do papel social que o outro, naquele determinado momento, interpreta.

\section{Considerações finais}

A proposta de humanizar e considerar de maneira racional a irracionalidade da loucura é o contraponto à formação acadêmica predominantemente biologicista das universidades brasileiras. Enquanto os conselhos profissionais insistem na busca do terreno de atuação de cada feudo profissional, as políticas de saúde mental e humanização propõem a contramão do mercado e da própria sociedade neoliberal: a horizontalidade nas relações humanas. Considerar o mesmo peso de importância entre o argumento academicista dos profissionais de saúde nas ações de cuidado e o argumento dos usuários, impregnados de uma subjetividade não científica, é essencial para o próprio sentido real dos diálogos em saúde que aqui propomos.

A Política Nacional de Humanização incentiva com suas propostas o protagonismo e a apropriação do SUS por parte da população e de seus trabalhadores; a Política Nacional de Saúde Mental propóe a voz aos destituídos da condição de cidadãos. A radicalidade das propostas de ambas é seu espaço comum. Encontrar o outro a partir da ótica humanista significa encarar o fato de que ele não pertence apenas ao aspecto clínico da produção de saúde: remete ao significado político do diálogo humano. Isso é o próprio processo democrático em sua essência de valor.

Acreditamos que a Política Nacional de Humanização, em seus dispositivos de atuação, e as propostas reformistas da legislação brasileira de saúde mental em suas propostas de cuidado à loucura, possuem em seu âmago a chave do encontro humano que produz o próprio sentido da existência do Sistema Único de Saúde. Não é excessivo lembrar que o direito constitucional à saúde é fruto da valorização 
da existência humana, mesmo que esta, perversamente, seja sujeitada pela ótica impessoal dos mecanismos institucionais. Interpretemos secundariamente nossos papéis institucionais, deixemos o papel principal à nossa porção humana e à unicidade que a define como tal. ${ }^{3}$

\section{Referências}

ALEKSANDROWICZ, A.M.C.; MINAYO, M.C.S. Humanismo, liberdade e necessidade: compreensão dos hiatos cognitivos entre ciências da natureza e ética. Revista Ciência e Saúde Coletiva, v.10, n.3, p.513-526, 2005.

ALVERGA, A.R. et al. Archivos de Saúde Mental e Atenção Psicossocial 2. Rio de Janeiro: Nau, 2005.

AMARANTE, P. Saúde Mental e Atenção Psicossocial. Rio de Janeiro: Fiocruz, 2007.

AYRES, J.R.C.M. Uma concepção hermenêutica da saúde. Physis: Revista de Saúde Coletiva, v.17, n.1, p.43-62, 2007.

BACKES, D.S.; KOERICH, M.S.; ERDMANN, A.L. Humanizing care through the valuation of the human being: resignification of values and principles by health professionals. Revista Latino Americana de Enfermagem, v.15, n.1, p.34-41, 2007.

BARBOSA, L.E.G. Filosofia como práxis y diálogo. Una Introducción a la hermenêutica desde Platón. Estudios de Filosofia, v.38, p.151-170, 2008.

BORNHEIM, G. Sartre, metafísica e existencialismo. São Paulo: Perspectiva, 2007.

BRASIL. Lei 8.080, de 19 de setembro de 1990. Lei Orgânica da Saúde. Dispõe sobre as condições de promoção, proteção e recuperação da saúde, a organização e o funcionamento dos serviços correspondentes e dá outras providências. Diário Oficial da União, 19 set 1990.

Lei 10.216, de 06 de abril de 2001. Dispõe sobre a proteção e os direitos das pessoas portadoras de transtornos mentais e redireciona o modelo assistencial em saúde mental. Diário Oficial da Uniāo, 06 abr 2001.

- Ministério da Saúde. Secretaria de Atenção à Saúde. Política Nacional de Humanização da Atenção e Gestão do SUS. Clínica Ampliada e Compartilhada. Brasília: Ministério da Saúde, 2009a.

- Ministério da Saúde. Secretaria de Atenção à Saúde. Política Nacional de Humanização da Atenção e Gestão do SUS. Gestão Participativa e Cogestão. Brasília: Ministério da Saúde, 2009b.

Ministério da Saúde. Secretaria de Atenção à Saúde. Política Nacional de Humanização da Atenção e Gestão do SUS. Redes de produção de saúde. Brasília: Ministério da Saúde, 2009c. 

. Ministério da Saúde. HumanizaSUS: documento base para gestores e trabalhadores do SUS. 4a ed. Brasília: Ministério da Saúde, 2010a.

- Ministério da Saúde. Secretaria de Atenção à Saúde. Núcleo Técnico da Política Nacional de Humanização. Acolhimento nas práticas de produção de saúde. Brasília: Ministério da Saúde, 2010b. . Ministério da Saúde. SAS/DAPES. Coordenação Geral de Saúde Mental, Álcool e outras drogas. Saúde Mental em Dados 7 - Edição especial. Ano V, n.7, 2010. Brasília, 2010c. - Ministério da Saúde. Secretaria de Atenção à Saúde. Departamento de Ações Programáticas e Estratégicas. Política Nacional de Humanização da Atenção e Gestão do SUS. Programa de Formação em saúde do trabalhador. Brasília: Ministério da Saúde, 2011.

CAMPOS, G.W.S. O anti-Taylor: sobre a invenção de um método para co-governar instituições de saúde produzindo liberdade e compromisso. Ciência Saúde Pública, v.14, n.4, p.863-870, 1998.

COUTO, C.G. Constituição, Competição e Políticas Públicas. Lua Nova, v.65, p.95-135, 2005. DELEUZE, G.; GUATTARI, F. Mil Platôs: Capitalismo e Esquizofrenia. v.1. Rio de Janeiro: 34, 2007.

DESLANDES, S.F. Humanização dos Cuidados em Saúde: conceitos, dilemas e práticas. Rio de Janeiro: Fiocruz, 2006.

ESCOSSIA, L.; KASTRUP, V. O conceito de coletivo como superação da dicotomia indivíduo-sociedade. Psicologia em Estudo, v.10, n.2, p.295-304, 2005.

FILHO, J.F.S. 1968 e a Saúde Mental. Rio de Janeiro: Contra Capa, 2008.

FILIPPON, J.G. Democracia e Conquista: Saúde Mental como política pública. Dissertação (Mestrado em Enfermagem) - Escola de Enfermagem de Ribeirão Preto, Universidade de São Paulo, Ribeirão Preto, 2009. 120p.

FOUCAULT, M. História da Loucura. São Paulo: Perspectiva, 2008.

LAHIRE, B. Indivíduo e misturas de gêneros: Dissonâncias culturais e distinção de si. Sociologia, v.56, p.11-36, 2008.

MARCONI, M.A.; LAKATOS, E.M. Fundamentos de Metodologia Científica. São Paulo: Atlas, 2010.

MARTÍN, J.P. Filosofia y política em los inícios de La filosofia. Circe de Clásicos y Modernos, v.9, p.137-155, 2004.

MOISÉS, J.A. A desconfiança nas instituições democráticas. Opiniāo Pública, v.11, n.1, p.33-63, 2005.

NIETZSCHE, F. A Gaia Ciência. São Paulo: Companhia das Letras, 2002. 
PAIM, J.S. Desafios para a Saúde Coletiva no Século XXI. Salvador: EdUFBA, 2007.

PAIM, J.S.; ALMEIDA FILHO, N. Saúde Coletiva: uma "nova saúde pública” ou campo aberto a novos paradigmas? Revista de Saúde Pública, v.32, n.4, p.299-316, 1998.

PINHEIRO, R.; LUZ, M.T. Práticas eficazes x modelos ideais: ação e pensamento na construção da integralidade. In: PINHEIRO, R.; MATTOS, R.A. (Org.). Construção da integralidade: cotidiano, saberes e práticas em saúde. $4^{\mathrm{a}}$ ed.Rio de Janeiro: Cepesc, 2007. p.9-36.

PIRELLA, A. et al. Psiquiatria Social e Reforma Psiquiátrica. Rio de Janeiro: Fiocruz, 2008. SANTOS-FILHO, S.B.; BARROS, M.E.B. Trabalhador da Saúde, Muito Prazer! Ijuí: EdUnijui, 2007.

SOARES, H.L.R.; CUNHA, C.E.C. A síndrome do "burn-out": sofrimento psíquico nos profissionais de saúde. Revista do Departamento de Psicologia da UFF, v.19, n.2, p.505-506, 2007.

\section{Notas}

${ }^{1}$ Observação dos autores.

${ }^{2}$ Percepção empírica dos autores através de suas vivências em foros participativos do Sistema Único de Saúde brasileiro.

${ }^{3}$ J. Filippon participou da criação do argumento do texto, desenvolvimento e revisão das ideias discutidas. L.P. Kantorski auxiliou no desenvolvimento e organização da argumentação apresentada no artigo. 
Humanization and madness, in search of the Human who dialogues health

Investing in the necessary theoretical relationship between Humanization and Mental Health Policies of the Brazilian health system, this paper argues, through the theoretical dialogue between them, the idea that the proposals set forth in such policies are coherent answers to the main contradictions of the intricate national public health system. So are presented: the theoretical basis of the aforementioned ministerial policies; their relations with the society demanded as public policy; and finally, how the combination of both provide essential contributions to the continuity of the Unified Health System (SUS). The essay methodology was used, according to updated methodological bibliography, listing authors and their contributions in order to defend the views of the authors. We conclude that the public encouragement of protagonizsm of society undermines the logic of biological training courses for health professionals and flattens human relations within the SUS, fortifying it and giving it essential reason for existence to the Brazilian society.

Key words: mental health; humanization; social control. 